\title{
Validation of multi-frequency bioelectrical impedance analysis versus dual-energy $X$-ray absorptiometry to measure body fat percentage in overweight/obeses Colombian adults
}

\author{
Robinson Ramírez-Vélez ${ }^{1}$ (D) | Alejandra Tordecilla-Sanders ${ }^{1}$ | \\ Jorge Enrique Correa-Bautista ${ }^{1}$ | Katherine González-Ruíz ${ }^{2}$ | \\ Emilio González-Jiménez $^{3,4}$ | Hector Reynaldo Triana-Reina ${ }^{5}$ | \\ Antonio García-Hermoso $^{6}$ | Jacqueline Schmidt-RioValle ${ }^{3,4}$
}

${ }^{1}$ Centro de Estudios para la Medición de la Actividad Física «CEMA», Escuela de Medicina y Ciencias de la Salud, Universidad del Rosario, Bogota DC 111221, Colombia

${ }^{2}$ Grupo de Ejercicio Físico y Deportes, Vicerrectoria de Investigaciones, Universidad Manuela Beltrán, Bogota DC 110231, Colombia

${ }^{3}$ Departamento de Enfermería, Facultad de Ciencias de la Salud, University of Granada, Avda. De la Ilustración, 60, 18016 Granada, Spain

${ }^{4}$ Grupo CTS-436, Adscrito al Centro de Investigación Mente, Cerebro y Comportamiento (CIMCYC), University of Granada, 18071 Granada, Spain

${ }^{5}$ Grupo GICAEDS, Facultad de Cultura Física, Deporte y Recreación, Universidad Santo Tomás, Bogota DC 110311, Colombia

${ }^{6}$ Laboratorio de Ciencias de la Actividad Física, el Deporte y la Salud, Universidad de Santiago de Chile, USACH, Santiago 7500618, Chile

\section{Correspondence}

Ramírez-Vélez Robinson, Centro de Estudios para la Medición de la Actividad Física «CEMA», Escuela de Medicina y Ciencias de la Salud, Universidad del Rosario, Bogota DC 111221, Colombia Email: robin640@ hotmail.com or robinson.ramirez@urosario.edu.co

\begin{abstract}
Objectives: To verify the validity of multi-frequency bioelectrical impedance analysis (mBCA) for predicting body fat percentage $(\mathrm{BF} \%)$ in overweight/obese adults using dual-energy X-ray absorptiometry (DXA) as the reference method.

Methods: Forty-eight adults participated ( $54 \%$ women, mean age $=41.0 \pm 7.3$ years old). The Pearson's correlation coefficient was used to evaluate the correlation between BIA and BF\% assessed by DXA. The concordance between BF\% measured by both methods was obtained with Lin's concordance correlation coefficient and Bland-Altman difference plots.
\end{abstract}

Results: Measures of BF\% were estimated as $39.0(\mathrm{SD}=6.1)$ and $38.3(\mathrm{SD}=6.5)$ using DXA and mBCA, respectively. The Pearson's correlation coefficient reflected a strong correlation $(r=.921, P=.001)$. The paired $t$-test showed a significant mean difference between these methods for obese men BF\% of -0.6 [(SD 1.95; 95\% $\mathrm{CI}=-4.0$ to 3.0), $P=.037]$. Overall, the bias of the mBCA was -0.6 [(SD 2.2; $95 \% \mathrm{CI}=-5.0$ to 3.7$), P=.041]$, which indicated that the mBCA method significantly underestimated $\mathrm{BF} \%$ in comparison to the reference method. Finally, in both genders, Lin's concordance correlation coefficient showed a strong agreement. More specifically the DXA value was $\rho c=0.943(95 \% \mathrm{CI}=0.775$ to 0.950$)$ and the mBCA value was $\rho c=0.948$ (95\% CI $=0.778$ to 0.978 ).

Conclusions: Our analysis showed a strong agreement between the two methods as reflected in the range of BF\%. These results show that mBCA and DXA are comparable methods for measuring body composition with higher body fat percentages. However, due to broad limits of agreement, we can only recommend mBCA for groups of populations. 


\section{1 | INTRODUCTION}

The prevalence of overweight and obesity is a public health problem that has become epidemic worldwide (Bhupathiraju $\& \mathrm{Hu}, 2016)$. Currently, various methods are used to identify adults at risk of excess adiposity. Among those methods the following stand out: magnetic resonance imaging, computed tomography, dual-energy X-ray absorption (DXA), isotopic measurement of body water, whole body plethysmography, bioelectrical impedance analysis (BIA), and underwater weighting (Lee \& Gallagher, 2008). The DXA method, which is considered very reliable, is often referenced in the literature and is regarded in clinical practice as the 'gold standard' for this kind of assessment (Buckinx et al., 2015). However, one of its drawbacks is the radiation emitted during measurement (Li et al., 2013).

A viable alternative to DXA is a bioelectrical approach. The Multi-frequency Bioelectrical Impedance Analyzer (Model Seca ${ }^{\circledR}$ mBCA 514 Medical Body Composition Analyze, Hamburg, Germany) is capable of accurately assessing people with very different body types, whether they are obese, elderly population, or athletic (Buckinx et al., 2015), and with its moderate cost ( $<$ US $\$ 12.000$ ), it is practical for population-based studies. Various studies have been conducted with a view to validating the BIA for the estimation of BF\% in comparison to DXA (Bosy-Westphal et al., 2008; Shafer, Siders, Johnson, \& Lukaski, 2009). However, little research has been performed on the validation of mBCA with multifrequency.

There is a need for simple adiposity indicators in the Latin-American population since such indexes may help clinicians estimate health risk as well as intervention effectiveness in obese adults (González-Ruíz, Correa-Bautista, \& Ramírez-Vélez, 2015). However, to our knowledge, no study has as yet assessed the Model Seca ${ }^{\circledR}$ mBCA 514 Medical Body Composition Analyzer as compared to DXA in the Latin-American adult population. Accordingly, the objective of this study was to verify the validity of the mBCA device and its associated algorithm in the prediction of $\mathrm{BF} \%$ in a sample of obese adults. The reference method used in this study was DXA.

\section{2 | METHODS}

The methodology for this study has been previously described (Ramírez-Vélez et al., 2016). The sample population for this study consisted of 48 voluntary participants (54\% women) with ages ranging from 30 to 50 years. All of the subjects had abdominal obesity (men waist circumference $\geq 90 \mathrm{~cm}$, women waist circumference, $\geq 80 \mathrm{~cm}$ ) or excess weight, both were defined above the sex-specific thresholds of the World Health Organization (WHO, 1998). Their body mass index (BMI) was $>25 \mathrm{~kg} / \mathrm{m}^{2}$ but $\leq 35 \mathrm{~kg} / \mathrm{m}^{2}$. Pregnant women, individuals with physical disabilities, and individuals who were bedridden at the time of data collection were excluded. The Institutional Ethics Committee in accordance with the most recent version of the Declaration of Helsinki approved the research design (UMB No 01-1802-2013). All participants signed a written informed consent form.

\section{1 | Design and procedures}

Anthropometric variables were assessed by a nutritionist in accordance with the guidelines of the International Society for the Advancement of Kinanthropometry (ISAK) (MarfellJones, Olds, \& Stewart, 2006). For this purpose, an electronic scale (Model Seca ${ }^{\circledR}$ mBCA 514 Medical Body Composition Analyzer, Hamburg, Germany) was used. Height was measured with a mechanical stadiometer platform (Seca ${ }^{\circledR}$ 274, Hamburg, Germany). BMI was calculated as weight divided by height squared $\left(\mathrm{kg} / \mathrm{m}^{2}\right)$. Subjects with a BMI $>25 \mathrm{~kg} / \mathrm{m}^{2}$ were thus regarded as overweight and with a BMI $>30 \mathrm{~kg} / \mathrm{m}^{2}$ as obese. Waist and hip circumferences (cm) were measured. The same tape measure (Ohaus ${ }^{\circledR} 8004$ MA, New Jersey) was used for both measurements with a $0.1 \mathrm{~mm}$ accuracy. In addition, we also calculated the waistto-height ratio (WHtR).

The BF\% of each participant was determined by means of a whole body DXA scan (Lunar Prodigy Advance; GEMedical Systems, Madison, Wisconsin) and software (enCore 2006, ver. 10.51.006; GE-Company, Madison, Wisconsin). Before the scan, subjects were asked to remove all metal objects. The analysis was performed with a tetrapolar whole body impedance (Model Seca ${ }^{\circledR}$ mBCA 514 Medical Body Composition Analyzer, Hamburg, Germany). The reproducibility of the variables estimated by DXA and mBCA were determined by the coefficient variation $(\mathrm{CV} \%)$ and technical error of measurement (TEM), based on the test-retest realized with 25 subjects out of the population of this study. The CV\% were $0.74 \%$ (DXA), $0.56 \%$ (BIA), and $0.27 \mathrm{~kg}$ (DEXA), $0.21 \mathrm{~kg}$ (BIA), respectively.

\section{2 | Statistical analysis}

Statistical analyses were performed using the Statistical Package for the Social Sciences (SPSS), Windows version 21.0 (IBM Corporation, New York). For the purposes of this study, $P$ values of $<.05$ were considered significant. The correlation between variables was assessed by the Pearson's correlation coefficient, based on gender. The closer the coefficient was to 1 , the higher the reliability. Therefore, a WHtR, over 0.90 was regarded as very high; a WHR of $0.70-0.89$ was high; and a WHR of $0.50-0.69$ was moderate (Koo \& Li, 2016). In addition, for each sex, paired sample $t$ tests tested differences in the mean BF\% obtained with the 
TABLE 1 Pearson's correlation coefficients between BF\% measured by DEXA and different anthropometric variables

\begin{tabular}{|llll|} 
& $\begin{array}{l}\text { Women } \\
(\boldsymbol{n}=\mathbf{2 6})\end{array}$ & $\begin{array}{l}\text { Men } \\
(\boldsymbol{n}=\mathbf{2 2})\end{array}$ & $\begin{array}{l}\text { Total } \\
(\boldsymbol{n}=\mathbf{4 8})\end{array}$ \\
\hline BF\% (mBCA) & $.864^{*}$ & $.919^{*}$ & $.921^{*}$ \\
\hline Weight $(\mathrm{kg})$ & $.696^{*}$ & $.465^{*}$ & $.568^{*}$ \\
\hline Waist $(\mathrm{cm})$ & $.626^{*}$ & $.596^{*}$ & $.446^{*}$ \\
\hline Hip $(\mathrm{cm})$ & $.818^{*}$ & $.685^{*}$ & $.705^{*}$ \\
\hline WHtR & $.663^{*}$ & $.639^{*}$ & $.336^{*}$ \\
\hline BMI $\left(\mathrm{kg} / \mathrm{m}^{2}\right)$ & $.670^{*}$ & $.739 *$ & $.557^{*}$ \\
\hline
\end{tabular}

Abbreviation: WHtR, waist-to-height ratio; BMI, body mass index.

*All reported correlation coefficients are significant at $P<.001$.

mBCA and DXA methods. Lin's concordance correlation coefficient assessed the reproducibility of BIA and DXA measures, based on gender. Finally, the Bland-Altman difference plot was used to verify the agreement between BIA and DXA.

\section{3 | RESULTS}

In the total sample, $\mathrm{BF} \%$ measures were estimated at 39.0 $(\mathrm{SD}=6.1)$ and $38.3(\mathrm{SD}=6.5)$ using DXA and mBCA, respectively. The Pearson's correlation coefficient reflected a strong correlation $(r=.921, P=.001)$.

Table 1 shows the coefficients of correlation between DXA and different anthropometric measurements. Stratified analyses according to gender showed that for males, there were significant correlations between $\mathrm{mBCA}$ and DXA in regard to $\mathrm{BF} \%(r=.919, P<.001)$, BMI $(r=.739$, $P<.001)$, and hip $(r=.685, P<.001)$. For females, significant correlations were found for all measurements evaluated when the group was considered in its totality. For men and women, the Lin's concordance correlation coefficient was strongest between $\mathrm{BF} \%$ as measured by DXA and mBCA. The values for DXA were $\rho c=0.943(95 \% \mathrm{CI}=0.775$ to $0.950)$ and those for BIA were $\rho c=0.948(95 \% \mathrm{CI}=0.778$ to 0.978 ).

Males and females were then divided according to BF\%. As can be observed in Table 2, it should be highlighted that females with a BMI $\geq 30$ had a higher correlation coefficient $(r=.970, P<.001)$. For males (BMI $\geq 30$ ), the correlation coefficient was also fairly high $(r=.868, P<.001)$.

The Bland-Altman plot (Figure 1) shows BF\% as measured by $\mathrm{mBCA}$ in relation to the gold standard, based on weight status and gender. For overweight men and women, the bias of the mBCA was -0.7 (SD 3.0) BF\% (95\% $\mathrm{CI}=-6.0$ to 4.0 ). For obese men and women, the bias of the mBCA was -0.6 (SD 1.82) $\mathrm{BF} \%(95 \% \mathrm{CI}=-4.2$ to

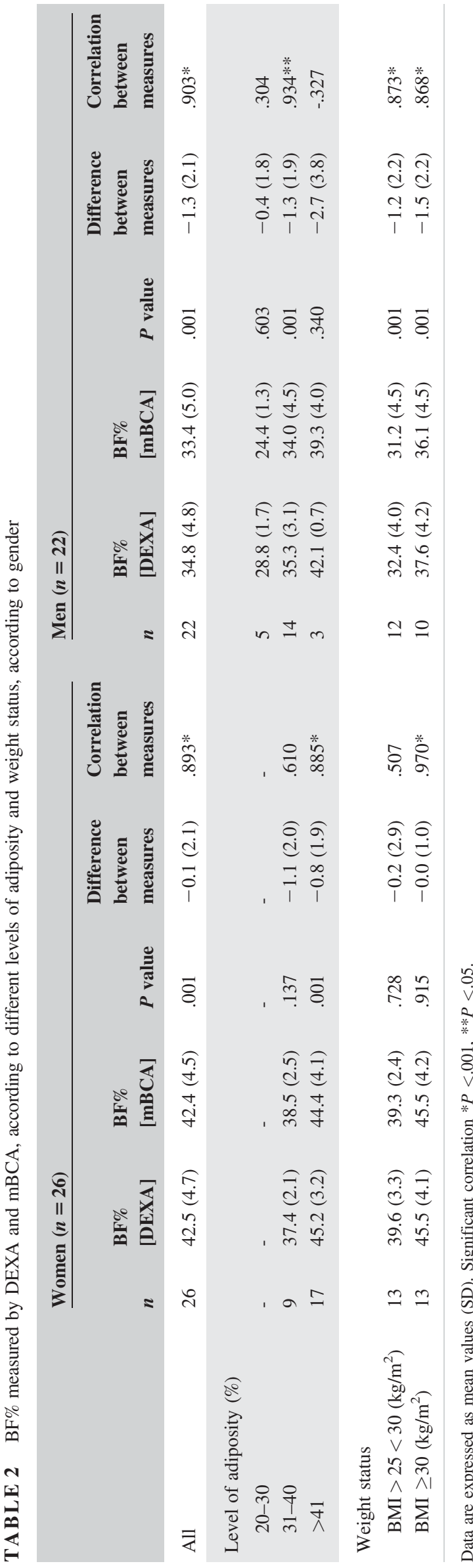



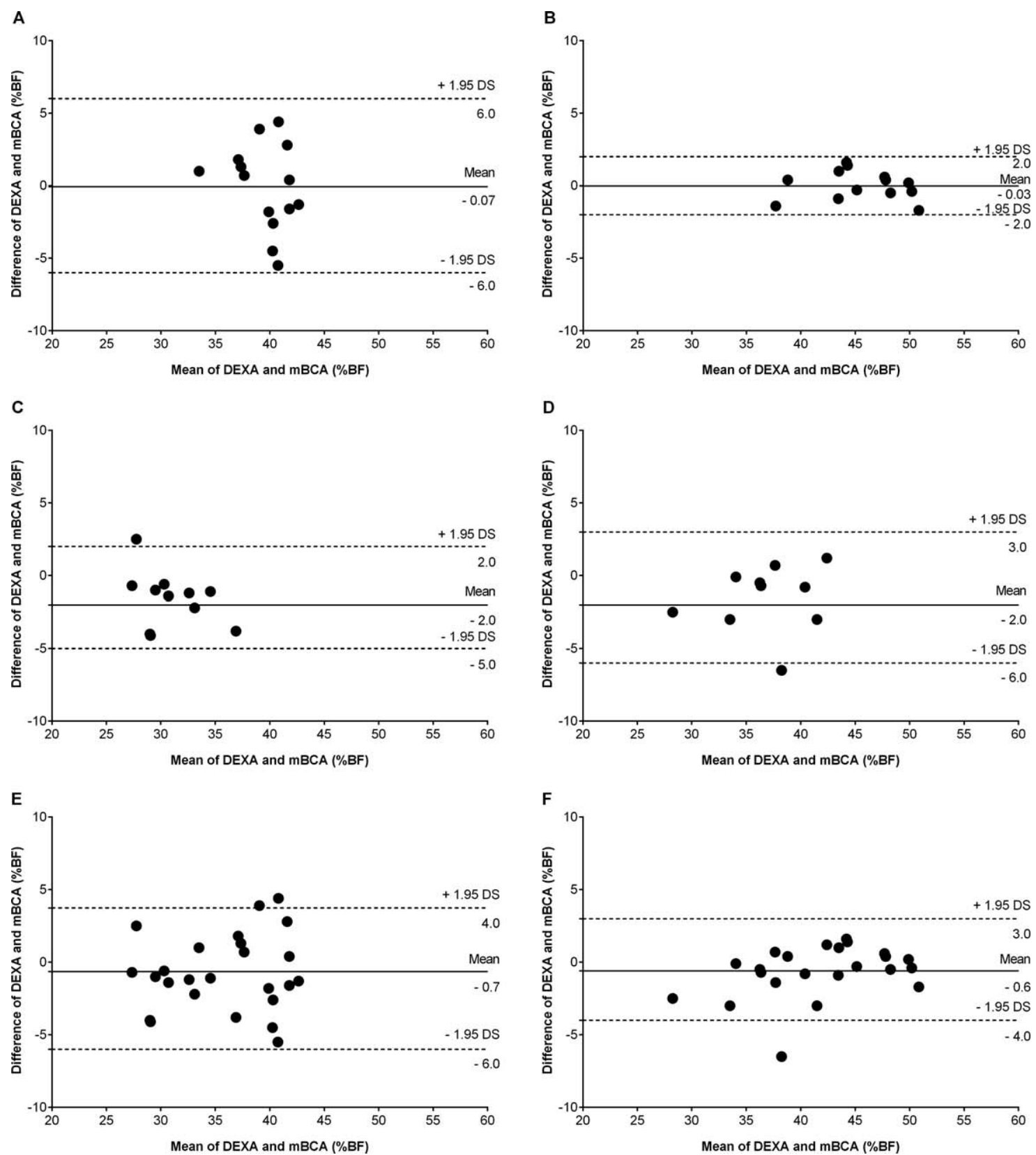

FIG URE 1 Bland-Altman plots of BF\% assessed according to weight status and sex: A, Women + Overweight BMI; B, Women + Obesity BMI; C, Men + Overweight BMI, D, Men + Obesity BMI; E, all participants + Overweight; and F, all participants + Obesity. The differences between the two methods are plotted based on their mean values. The solid line represents the mean value of the two methods and dashed lines, the SD 1.96

2.9). Oveall, the bias of the mBCA was - -0.6 [(SD 2.2; $95 \%$ $\mathrm{CI}=-5.0$ to 3.7), $P=.041$, which indicated that the $\mathrm{mBCA}$ method significantly underestimated $\mathrm{BF} \%$ in comparison to the reference method. It was observed that in the total sample, as well as in the male and female groups, the confidence interval for overweight subjects was greater than for obese subjects.

\section{4 | DISCUSSION}

Our results reflected a strong correlation between $\mathrm{BF} \%$ measured by DXA and mBCA in the sample population. However, the wide limits of agreement (Figure 1) limits the applicability of the mBCA for predicting BF\% in individuals. Although various studies have compared BIA with DXA as the reference method (Erceg et al., 2010; Lazzer, Boirie, Meyer, \& Vermorel, 2003; Lloret-Linares et al., 2011; Neovius, Hemmingsson, Freyschuss, \& Uddén, 2006; Newton et al., 2005, 2006; Verdich et al., 2011), they focused on populations of other age ranges and also used different measuring devices. Generally speaking, cross-sectional studies of BF\% reported that BIA overestimated BF\% (Lloret-Linares et al., 2011; Newton et al., 2005; Sato, Demura, Kitabayashi, \& Noguchi, 2007; Shafer et al., 2009), whereas others revealed that BIA underestimated 
BF\% (Bosy-Westphal et al., 2008; Lloret-Linares et al., 2011; Sato et al., 2007; Verdich et al., 2011). This was also reflected in the results of our study. Nevertheless, it is difficult to compare our findings with those of other researchers because of the difference in devices used, such as foot-to-foot BIA (Erceg et al., 2010; Lazzer et al., 2003; Newton et al., 2005, 2006), devices with adhesive tape (Aslam et al., 2009; Bosy-Westphal et al., 2008; Neovius et al., 2006), and multi-frequency devices (Kim, Gallagher, \& Song, 2005; Shafer et al., 2009).

In Sato et al. (2007), where all participants were obese, BF\% obtained with BIA was underestimated in women and overestimated in male subjects. This coincided with the results for men obtained in our study. In the case of Verdich et al. (2011), BF\% measured with BIA in 771 obese adults was underestimated for both genders. Nevertheless, the measuring device used was a four-electrode segmental BIA. Aslam et al. (2009) studied 34 obese men and women and concluded that BIA was a valid method for estimating BF\%. Furthermore, the results of other studies indicate that the nutritional status of the participants should be considered since it is a conditioning factor that can potentially influence the validity of the BIA as a method for determining BF\% (Sato et al., 2007).

The primary limitations of this study are that the subjects were studied on a single occasion; it would be interesting to carry out the assessment at two time-points, to see if these results are the same for changes in fat mass over time. The second limitation is the absence of normal-weight participants in the sample. Due to this and other limitations (e.g., relatively small sample size; single site design), it is important to not over-interpret the results of this cross-sectional study (Aslam et al. 2009; Kim et al., 2005; Lazzer et al. 2003; Newton et al. 2005). However, most adult studies have not shown gender differences in the predictability of BIA equations.

In conclusion, the results reflected a strong correlation between BF\% measured by DXA and mBCA in the sample population. However, the wide limits of agreement limits the applicability of the mBCA for predicting BF\% in overweight and obese individuals in the Colombian population. Although further studies need to be carried out, the research presented in this article provides valuable new data for the Latin American context.

\section{ACKNOWLEDGMENTS}

The authors thank the study subjects who participated in the study.

\section{CONFLICT OF INTERESTS}

The authors declare that they have no conflict of interest.

\section{AUTHOR CONTRIBUTIONS}

Robinson Ramírez-Vélez, Katehrine González-Ruíz, Alejandra Tordecilla-Sanders, and Jorge Enrique Correa-
Bautista conceived and designed the study, and analyzed the data; Emilio González-Jiménez, Antonio GarciaHermoso, Hector Reynaldo Triana-Reina, and Jacqueline Schmidt-RioValle analyzed the data and wrote the article. All authors read and approved the final manuscript.

\section{ORCID}

Robinson Ramírez-Vélez (D) http://orcid.org/0000-0003-30756960

\section{REFERENCES}

Aslam, M., Eckhauser, A. W., Dorminy, C. A., Dossett, C. M., Choi, L., \& Buchowski, M. S. (2009). Assessing body fat changes during moderate weight loss with anthropometry and bioelectrical impedance. Obesity Research \& Clinical Practice, 3, 209-219.

Bhupathiraju, S. N., \& Hu, F. B. (2016). Epidemiology of obesity and diabetes and their cardiovascular complications. Circulation Research, 118, 1723-1735.

Bosy-Westphal, A., Later, W., Hitze, B., Sato, T., Kossel, E., Gluer, C. C., .. Muller, M. J. (2008). Accuracy of bioelectrical impedance consumer devices for measurement of body composition in comparison to whole body magnetic resonance imaging and dual X-ray absorptiometry. Obesity Facts, 1, 319-324.

Buckinx, F., Reginster, J. Y., Dardenne, N., Croisiser, J. L., Kaux, J. F., Beaudart, C., ... Bruyère, O. (2015). Concordance between muscle mass assessed by bioelectrical impedance analysis and by dual energy X-ray absorptiometry: A cross-sectional study. BMC Musculoskeletal Disorders, 16, 60.

Erceg, D. N., Dieli-Conwright, C. M., Rossuello, A. E., Jensky, N. E., Sun, S., \& Schroeder, E. T. (2010). The Stayhealthy bioelectrical impedance analyzer predicts body fat in children and adults. Nutrition Research, 30, 297-304.

González-Ruíz, K., Correa-Bautista, J. E., \& Ramírez-Vélez, R. (2015). Body adiposity and its relationship of metabolic syndrome components in Colombian adults. Nutricion Hospitalaria, 32, 1468-1475.

Kim, H., Gallagher, D., \& Song, M. (2005). Comparison of body composition methods during weight loss in obese women using herbal formula. The American Journal of Chinese Medicine, 33, 851-858.

Koo, T. K., \& Li, M. Y. (2016). A guideline of selecting and reporting intraclass correlation coefficients for reliability research. Journal of Chiropractic Medicine, 15, 155-163.

Lazzer, S., Boirie, Y., Meyer, M., \& Vermorel, M. (2003). Evaluation of two foot-to-foot bioelectrical impedance analysers to assess body composition in overweight and obese adolescents. British Journal of Nutrition, 90, 987-992.

Lee, S. Y., \& Gallagher, D. (2008). Assessment methods in human body composition. Current Opinion in Clinical Nutrition \& Metabolic Care, 11, 566-572.

Li, Y.-C., Li, C.-I., Lin, W.-Y., Liu, C.-S., Hsu, H.-S., Lee, C.-C., . . Lin, C. C. (2013). Percentage of body fat assessment using bioelectrical impedance analysis and dual-energy X-ray absorptiometry in a weight loss program for obese or overweight Chinese adults. PLoS ONE, 8, e58272. 
Lloret-Linares, C., Ciangura, C., Bouillot, J. L., Coupaye, M., Declèves, X., Poitou, C., ... Oppert, J. M. (2011). Validity of leg-to-leg bioelectrical impedance analysis to estimate body fat in obesity. Obesity Surgery, 21(7), 1.

Marfell-Jones, M., Olds, T., \& Stewart, A. (2006). International standards for anthropometric assessment. Potchefstroom, South Africa: ISAK.

Neovius, M., Hemmingsson, E., Freyschuss, B., \& Uddén, J. (2006). Bioelectrical impedance underestimates total and truncal fatness in abdominally obese women. Obesity, 14, 1731-1738.

Newton, R., Alfonso, A., White, M., York-Crowe, E., Walden, H., Ryan, D., ... Williamson, D. (2005). Percent body fat measured by BIA and DXA in obese, African-American adolescent girls. International Journal of Obesity, 29, 594-602.

Newton, J. R., Alfonso, A., York-Crowe, E., Walden, H., White, M., Ryan, D., \& Williamson, D. A. (2006). Comparison of body composition methods in obese African-American women. Obesity, (Silver Spring), 14, 415-422.

Ramírez-Vélez, R., Correa-Bautista, J. E., González-Ruíz, K., Vivas, A., García-Hermoso, A., \& Triana-Reina, H. R. (2016). Predictive validity of the body adiposity index in overweight and obese adults using dual-energy X-ray absorptiometry. Nutrients, 8, 737.

Sato, S., Demura, S., Kitabayashi, T., \& Noguchi, T. (2007). Segmental body composition assessment for obese Japanese adults by single-frequency bioelectrical impedance analysis with 8-point contact electrodes. Journal of Physiological Anthropology, 26, 533-540.

Shafer, K. J., Siders, W. A., Johnson, L. A. K., \& Lukaski, H. C. (2009). Validity of segmental multiple-frequency bioelectrical impedance analysis to estimate body composition of adults across a range of body mass indexes. Nutrition, 25, 25-32.

Verdich, C., Barbe, P., Petersen, M., Grau, K., Ward, L., Macdonald, I., .. Oppert, J. M. (2011). Changes in body composition during weight loss in obese subjects in the NUGENOB study: Comparison of bioelectrical impedance vs. dual-energy X-ray absorptiometry. Diabetes \& Metabolism, 37, 222-229.

World Health Organization. (1998). Programme of nutrition, family and reproductive health. Obesity. Preventing and managing the global epidemic. Ginebra: Report of a WHO consultation on obesity.

How to cite this article: Ramírez-Vélez R, TordecillaSanders A, Correa-Bautista JE, et al. Validation of multi-frequency bioelectrical impedance analysis versus dual-energy X-ray absorptiometry to measure body fat percentage in overweight/obeses Colombian adults. Am J Hum Biol. 2018;30:e23071. https://doi.org/10.1002/ ajhb.23071 